\title{
Depression, quality of life and cortisol: a cross-sectional study
}

\section{of caregivers of patients with Alzheimer's disease [version 1;}

\section{peer review: 1 approved, 1 approved with reservations]}

\author{
Emanuela Bernardi (D1), Katiuscia de Oliveira Francisco Gabriel2, Luana Bernardi3, \\ Gláucia Renée Hilgemberg1', Elizama de Gregório (iD), \\ Weber Cláudio Francisco Nunes da Silva1', Caryna Eurich Mazur³, \\ Etiene Rabel Corso5, Juliana Maria Silva Valério ${ }^{1}$, Camila Diedrich ${ }^{6}$, \\ Juliana Sartori Bonini (D)1
}

\footnotetext{
${ }^{1}$ Pharmacy Department, Campus CEDETEG, Midwest State University, Guarapuava, Paraná, 85040-080, Brazil 2Physiotherapy Department, Campus CEDETEG, Midwest State University, Guarapuava, Paraná, 85040-080, Brazil

${ }^{3}$ Faculty of Medicine, Campus Campo Grande, Federal University of Mato Grosso do Sul, Campo Grande, Mato Grosso do Sul, $79070-$ 900, Brazil

${ }^{4}$ Departamento de Fisiologia Humana, Universidade Federal do Rio Grande do Sul, Porto Alegre, Rio Grande do Sul, 90040-060, Brazil

${ }^{5}$ Faculdade Guairacá, Department of Social Assistance, Guarapuava, Paraná, 85010-000, Brazil

${ }^{6}$ Chemistry Department, Campus Pato Branco, Federal Technological University of Paraná, Pato Branco, Paraná, 85503-390, Brazil
}

V1 First published: 29 May 2018, 7:672

https://doi.org/10.12688/f1000research.14435.1

Latest published: 29 May 2018, 7:672

https://doi.org/10.12688/f1000research.14435.1

\section{Abstract}

Background: Stress can impact human health in multiple ways. Among the related mechanisms are the hormonal systems of the hypothalamic-pituitary-adrenal axis, which produces cortisol. Current research aims to evaluate the relationship between the daily variation of salivary cortisol dosages and the level of stress in caregivers of patients with Alzheimer's disease (AD).

Methods: A sociodemographic questionnaire was applied to 25 caregivers, as well as the 36 Item Short-Form Health Survey and Beck's Depression Inventory. In the 25 patients of the caregivers, the Instrumental Activities of Daily Living of the patient and Clinical Dementia Rating were assessed. Saliva samples were collected to assess the cortisol level of the caregivers three times over one day for each caregiver, (morning, afternoon and evening) to investigate the correlation of the aforementioned questionnaires with the age and degree of kinship among caregivers of elderly patients to investigate the correlation with the results of the previously described tests, and the age and degree of relatedness of caregivers and elderly patients. Results: There was a significant positive correlation between daily cortisol levels and increasing caregiver age. However, the daily dosage of salivary cortisol was not significantly associated with the stress level

\section{Open Peer Review}

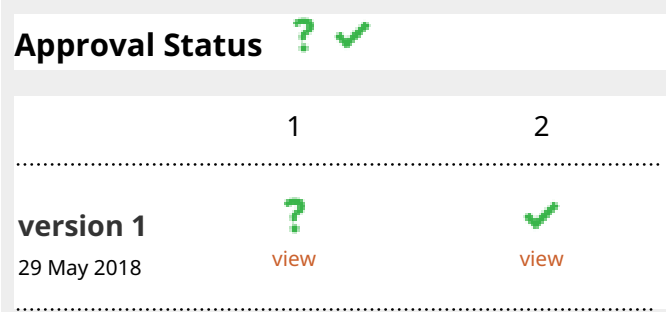

1. Helané Wahbeh ID , Institute of Noetic Sciences, Petaluma, USA

2. Maria F.B. Sousa, Federal University of Rio de Janeiro, Rio de Janeiro, Brazil

Any reports and responses or comments on the article can be found at the end of the article. 
of the caregivers of patients with $A D$, suggesting that this is not a good neuroendocrine marker of response to mood disorders. This fact can be related to intrinsic and extrinsic factors to the caregiver. Conclusions: Compared with previous studies that correlate cortisol and stress in humans, our findings suggest that the stress mechanism may be more complex and depend on more factors than the levels of this hormone. Thus, further work is required to delineate possible cortisol modulators, as well as the type of stress that target this population and their ability to adapt and face adversity in their work.

\section{Keywords}

salivary cortisol, caregivers, cognitive deficits

\section{Corresponding author: Juliana Sartori Bonini (juliana.bonini@gmail.com)}

Author roles: Bernardi E: Writing - Original Draft Preparation, Writing - Review \& Editing; de Oliveira Francisco Gabriel K: Data Curation, Investigation; Bernardi L: Formal Analysis, Supervision, Writing - Review \& Editing; Renée Hilgemberg G: Supervision, Visualization; de Gregório E: Supervision, Visualization; Cláudio Francisco Nunes da Silva W: Formal Analysis, Methodology, Supervision; Eurich Mazur C: Formal Analysis, Methodology; Rabel Corso E: Investigation; Maria Silva Valério J: Supervision; Diedrich C : Writing - Review \& Editing; Sartori Bonini J: Methodology, Supervision, Validation, Visualization

Competing interests: No competing interests were disclosed.

Grant information: This study was funded by the Association of studies, research and assistance to people with Alzheimer's disease (AEPAPA), the Araucaria Foundation and Coordination of Improvements of Higher Education Personnel (CAPES).

The funders had no role in study design, data collection and analysis, decision to publish, or preparation of the manuscript.

Copyright: ๑ 2018 Bernardi E et al. This is an open access article distributed under the terms of the Creative Commons Attribution License, which permits unrestricted use, distribution, and reproduction in any medium, provided the original work is properly cited. The author(s) is/are employees of the US Government and therefore domestic copyright protection in USA does not apply to this work. The work may be protected under the copyright laws of other jurisdictions when used in those jurisdictions.

How to cite this article: Bernardi E, de Oliveira Francisco Gabriel K, Bernardi L et al. Depression, quality of life and cortisol: a crosssectional study of caregivers of patients with Alzheimer's disease [version 1; peer review: 1 approved, 1 approved with reservations] F1000Research 2018, 7:672 https://doi.org/10.12688/f1000research.14435.1

First published: 29 May 2018, 7:672 https://doi.org/10.12688/f1000research.14435.1 


\section{Introduction}

Population aging brings with it an increase in the incidence and prevalence of dementias, such as Alzheimer's disease (AD) ${ }^{1}$. $\mathrm{AD}$ is characterized by a progressive decline in cognitive and functional abilities, requiring an increasing need for clinical care of patients ${ }^{2,3}$. Studies have shown that these caregivers are subject to chronic diseases caused by their intense work routine with patients ${ }^{4-6}$.

Research indicates that stress can lead to a number of changes in the individual's brain ${ }^{7,8}$. Deficits in the domains of attention, working memory and executive function, mediated by the prefrontal cortex ${ }^{7}$ have already been verified in caregivers of patients with dementia ${ }^{9,10}$. In addition, the impairment of declarative memory dependent on the hippocampus region may also result from the chronic physical and emotional overload suffered by these caregivers ${ }^{11,12}$.

The main reason for the cognitive impairment of chronically stressed individuals is hypothalamic-pituitary-adrenal (HPA) axis dysfunction coupled to changes in glucocorticoid levels, especially cortisol, and changes in lower affinity receptors of these hormones. Hypercortisolemia, besides being neurotoxic when prolonged $^{13}$, may induce changes in the morphology and physiology of structures related to cognitive functions in the organism ${ }^{14}$.

Another condition related to prolonged periods of stress, excessive release of glucocorticoids and hyperactivity of the HPA axis is in hypocortisolemia, induced in these cases by failures in the ability of self-adjustment of allostatic systems ${ }^{15}$. Two theories justify the etiology of hypocortisolemia; the first correlates hypocortisolemia with the increase of the negative feedback sensitivity of the HPA axis ${ }^{16}$ and the second relates to adrenal insufficiency, caused by the chronicity of the response. Thus, the individual initially develops hypercortisolemia; however, the HPA axis collapses or fatigues and leading to hypocortisolemi ${ }^{15}$.

Allostatic biological mechanisms usually develop in the organism in an individual way based on the experiences lived by the individual, especially in the form of adaptive responses to stress. These are usually coordinated and involve different functional systems, particularly the nervous, endocrine and immune systems. Regarding the functioning of the HPA axis, research shows that as adults experience life events associated with stressful problems, innumerable biological triggers are developed that are associated with the incidence of psychopathologies ${ }^{17}$.

There is a growing body of evidence linking hormones besides cortisol as being responsible for stress responses, including progesterone and dehydroepiandrosterone (DHEA) $)^{18}$, and brainderived neurotrophic factor $(\mathrm{BDNF})^{19-24}$. Improved understanding of stressors, their mechanisms and co-influences are essential for a better understanding of the physiology of stress and of psychological disorders that are implicated in this physiological condition. Thus, the objective of this study was to evaluate the relationship between the daily variation of salivary cortisol dosages and the level of depression in caregivers of patients with $\mathrm{AD}$.

\section{Methods}

\section{Participants}

The study population consisted of caregivers of elderly patients with $\mathrm{AD}(\mathrm{n}=25)$ and patients admitted to the Association for Research and Assistance to Patients with Alzheimer's (AEPAPA) $(n=25)$ in the city of Guarapuava (PR). In order to determine the size of the sample, we considered all patients that fit the inclusion criteria of the study and are serviced by AEPAPA. In this study, the age cut-off used to classify patients as elderly was based on the criteria proposed by the World Health Organization (WHO), which defines individuals aged 60 years or older from developing countries as elderly. In order to identify and select the caregivers, AEPAPA was asked for an official list, containing identification, address and telephone number of the registered elderly. Subsequently, the cadastral data was confirmed with the Social Worker, with the intention of eliminating the names of the deceased or who had changed their residence or changed their city. A telephone appointment was initially made by the social worker of the AEPAPA. In case of refusal or absence (three attempts were made to contact each domicile), the subject was excluded. On the day of the visit, the professional, together with a nurse from the AEPAPA, made the verbal invitation to participate in the research, by means of a previous explanation of all the stages of the study and, later completing the Informed Consent Form (TCLE) by the participants. In the case of illiterate caregivers, the informed consent form was signed by a family member responsible after reading the terms to the caregiver. AEPAPA is a Civil Society with a care purpose, responsible for providing home care to the elderly, with Public Utility, according to Law No. 2157/2013, contained in the Official Gazette of the Municipality from August 24 to 30, 2013. The ethical precepts of voluntary, enlightened and consensual participation of each participant were respected through a Free and Informed Consent Term - informed consent form signed by the participant (caregiver and patient). The project was approved by the Ethics Committee on Human Research of the Health Sciences Sector, the State University of West Paraná Center (896 296/2014).

\section{Procedure}

This descriptive cross-sectional study began with the collection of data and salivary material from caregivers in the home of the elderly with $\mathrm{AD}$, by a team composed of a nurse, a psychologist, a social worker, a pharmacist and a nutritionist from AEPAPA in the period from December 2014 to December 2015. The study was quantitative and used formal instruments to collect the data as questionnaires, scales and tests based on the work of 25. Initially, the caregivers who agreed to participate were asked to refrain from eating, drinking caffeine, brushing their teeth and vigorous exercise for $2 \mathrm{~h}$ before the collection of cortisol.

Participants provided the first saliva sample in the morning, between 08:00 and 09:00 hours, after which the questionnaires 
were applied to the caregiver and the elderly patient. Initially, the sociodemographic characterization of the caregivers was based on the following aspects: relationship to the elderly patient, age, race, marital status, number of children, schooling, income, type of housing, hygiene conditions and basic sanitation in the residence where they performed their care work. The remaining tests included information such as the analysis of the caregiver's quality of life through the 36-Item Short Form Survey (SF-36) and the investigation of affective and somatic cognitive behavioral manifestations in the face of a possible picture of depression presented by the caregiver with the application of the Beck Depression Inventory (BDI), as well as the evaluation of the Instrumental Activities of Daily Living of the patient (IADL) with the help of the Lawton Scale, which focuses on assessing the elderly person's ability to maintain an independent life that interferes with the degree of caregiver activity, and classification of the stage of Alzheimer's disease using the Clinical Dementia Rating $(\mathrm{CDR})^{26-29}$.

The other saliva samples were collected in the afternoon, between 16:00 and 17:00 hours, and at night, between 22:00 and 23:00 hours, taking into account the circadian fluctuations of cortisol. After collection in a Salivette tube (Salivette ${ }^{\circledR}$, Sarstedt, Alemanha), since the biochemical dosage was performed on the saliva, the samples were immediately stored in a test tube (typically Ultra-High Performance $15 \mathrm{ml}$ centrifuge tubes; VWR, Radnor, PA). At the end of the sample collection, the samples were sent to the Master Laboratory, a private clinical laboratory, in Guarapuava, PR, with no charge on the patient.

In the laboratory, the samples were refrigerated in a freezer $\left(-4^{\circ} \mathrm{C}\right)$ for 24 hours until processing. Extraction of Salivette cotton saliva was performed by centrifugation (10 $\mathrm{min}$ at 3000 rpm) being the cortisol dosage in the saliva was performed by electrochemiluminescence immunoassay according to the instructions of the manufacturer (ECLIA; catalog number 11875116160; Roche Diagnosis GmbH, Mannheim, Germany).

\section{Quality of life questionnaire SF-36}

The SF-36 questionnaire, applied to caregivers in the study, has the advantage of being easy to understand and requiring a short application time; therefore, it is well suited to assessing the associations of several types of diseases with the quality of life of those involved. SF-36 consists of 36 general questions grouped into eight domains: functional capacity (10 items), vitality ${ }^{4}$, physical $^{4}$, pain $^{2}$, general health ${ }^{5}$, social ${ }^{2}$, emotional $^{3}$ and mental health ${ }^{5}$. Each of these questions is answered with a value between 0 and 100 , where 0 is the worst state of health and 100 is the perfect state of health ${ }^{26}$.

\section{BDI}

The BDI, applied to caregivers in the study, is an instrument structured in 21 descriptions of affective and somatic cognitive symptoms of depression, with answers to each question ranging from 0 to 3 points dealing with the absence of depressive symptoms until the presence of symptoms. Originally created by Aaron Temkin $\mathrm{Beck}^{30}$, satisfactory evidence of its trustworthiness and validity was shown by a study by Cunha, 200131. To get a total score to be evaluated, the points of each item are added, giving a total score whose maximum does not exceed 63 points. According to Caixeta, scores from 0 to 9 points indicate an absence of depression or minimal depressive symptoms; from 10 to 18 points indicate mild to moderate depression, from 19 to 29 points indicate moderate to severe depression, and 30 to 63 points indicate severe depression ${ }^{28}$.

\section{IADL with the Lawton Scale}

The evaluation of the implementation capacity of IADL was performed by applying the Lawton Scale to patients with AD in the study. For each task, there are three possible answers, with scores ranging from 1 to 3 (1, dependence; 2 , ability to perform the task with help; and 3, independence). The final score is reached by the sum of points of the eight domains and ranges from 8 to 24; the higher the score, the more independent the individual ${ }^{27,32}$.

\section{AD stage rating}

The AD CDR scale, applied to elderly patients in the study, was developed in 1979 at University of Washington's, St. Louis, Missouri, through the project" Memory and Aging"33, to graduate dementia and classify patients according to the disease stage, evaluating the presence or absence of cognitive impairment on a five-point scale $(0,0.5,1,2,3)$. The six domains analyzed by the test were: memory, orientation, judgment and problem solving, community function, home and hobby function, and personal care. A general CDR score was then performed using the individual ratings in the 6 areas, according to the standard scoring rules ${ }^{34}$; so that a CDR score of 0 indicates no dementia, while CDR scores of $0.51,2$ and 3 indicate very mild, mild, moderate and severe dementia, respectively. In addition, individual domain scores can be summed, totaling a score ranging from $0(0 \times 6$ : when there is no impairment in any domain) to $18(3 \times 6$ : when there is maximum commitment in all domains $)^{29}$.

\section{Data analysis}

To describe the results, descriptive tests were carried out with measures of central tendency and frequencies. To verify normality of the sample, the Shapiro-Wilk test was calculated. Pearson's and Spearman's correlation analyses were applied to parametric and non-parametric data, respectively. Also, for the association between CDR and cortisol values, the Kruskal-Wallis test was applied. The level of significance was set at 5\% $(\mathrm{P}<0.05)$. The analyses were performed using the Statistical Package for the Social Sciences software version 22.0.

\section{Results}

Demographic information

Of the total sample, $88.0 \% \quad(n=22)$ of the caregivers were female, $68.0 \%(n=17)$ of whom were Caucasian. Regarding marital status, $56.0 \%$ of participants $(n=14)$ were married and $84.0 \%(n=21)$ had up to 4 children, while $16.0 \%(n=4)$ reported having 5 to 8 children. Regarding the level of education, $8.0 \%$ of caregivers $(n=2)$ were illiterate, $44.0 \%(n=11)$ did not complete elementary school and only $4.0 \%(n=1)$ had completed higher 
education. Regarding the type of housing, 92.0\% ( $\mathrm{n}=23)$ resided in brick houses, while $8 \%(\mathrm{n}=2)$ reported living in wooden houses. $76.0 \%(n=19)$ rated their hygiene conditions as good, compared to $24 \% \quad(n=6)$ who reported very good hygiene conditions; all caregivers had water, electricity and sewage in their homes. As to income, $88.0 \%(n=22)$ of caregivers reported monthly income less than two minimum wages, equivalent to US $\$ 583.00$. By contrast, only $12 \%(n=3)$ reported an income of up to three minimum wages.

The distribution of participants in terms of their relationship to the patients was predominantly close to the patients, with $44.0 \%$ $(n=11)$ and $24.0 \%(n=6)$ of caregivers self-described wives or husbands, respectively. Caregivers were family members in $80.0 \%(n=20)$ of cases; among these, $24.0 \%(n=6)$ of caregivers self-declared as wives or husbands, $8.0 \%(\mathrm{n}=2)$ as grandchildren and $4.0 \% \quad(n=1)$ nephews. The remaining $20.0 \% \quad(n=5)$ were unrelated caregivers.

\section{Questionnaires}

With respect to depression affecting caregivers, values obtained from the BDI resulted in a mean score of $15.68(\mathrm{SD}=10.05)$, indicating mild to moderate depression in $36.0 \% \quad(n=9)$ of the caregivers, while $20.0 \% \quad(n=5)$ of caregivers were classified as having moderate to severe depression, $12.0 \% \quad(n=3)$ as having severe depression and $32.0 \% \quad(n=8)$ as not having depression.

SF-36 variables showed close variations between functional capacity and social aspects among caregivers, with a mean score of $74.2(\mathrm{SD}=28.7)$ for the functional capacity and 64.4 $(\mathrm{SD}=28.1)$ for the social aspect. Regarding functional capacity, the variable with the lowest mean score was the physical aspect (mean $=50, \mathrm{SD}=46.8$ ), compared to the aspects of pain (mean=53, $\mathrm{SD}=22.9$ ), general health status (mean=52.7, $\mathrm{SD}=15.6$ ) and vitality (mean=53.2, $\mathrm{SD}=19$ ). As for the social aspects, the emotional variable (mean $=40, \mathrm{SD}=48.1$ ) had the lowest score compared with mental health (mean=54.2, $\mathrm{SD}=21.7)$.

In the evaluation of IADL, the results showed that $70.83 \%$ $(\mathrm{n}=17)$ of patients with $\mathrm{AD}$ were not able to maintain an independent life, and $20.83 \%(n=5)$ were unable to perform any of the nine corresponding functions of the scale. In total, $50.0 \%$ $(n=12)$ performed some activity with partial help, and $29.17 \%$ $(n=7)$ were able to perform the activities without help. One patient did not participate in the questionnaire.

Regarding the stage of the disease $16.0 \% \quad(n=4)$ were in the mild stage of $\mathrm{AD}$ (CDR 1), $52.0 \%(\mathrm{n}=13)$ in the moderate stage (CDR 2$)$ and $32.0 \%(n=8)$ in the severe stage (CDR 3$)$.

\section{Cortisol levels in caregivers}

For the salivary cortisol test, 3 samples were collected from each patient, accounting for a total of 75 samples. With regard to the salivary cortisol dosage in the morning, the median value was $0.50 \mu \mathrm{g} / \mathrm{dl}$, with a minimum of $0.33 \mu \mathrm{g} / \mathrm{dl}$ and maximum of $1.27 \mu \mathrm{g} / \mathrm{dl}$ (reference value, approximately $0.69 \mu \mathrm{g} / \mathrm{dl}$ ). Salivary cortisol measured in the afternoon resulted in a median value of $0.32 \mu \mathrm{g} / \mathrm{dl}$, with a minimum of $0.09 \mu \mathrm{g} / \mathrm{dl}$ and a maximum of $0.71 \mu \mathrm{g} / \mathrm{dl}$ (reference value, approximately $0.43 \mu \mathrm{g} / \mathrm{dl}$ ). For the tests performed in the evening, the median value was $0.68 \mu \mathrm{g} / \mathrm{dl}$, with a minimum of $0.32 \mu \mathrm{g} / \mathrm{dl}$ and a maximum of $1.26 \mu \mathrm{g} / \mathrm{dl}$ (reference value, approximately $0.35 \mu \mathrm{g} / \mathrm{dl})$. The cortisol values were analyzed according to the values cited by Aardal and Holm, $1995^{35}$.

As analyzed in the paragraph above, the percentage of caregivers who presented cortisol at normal concentration was considerably higher than the percentage of caregivers who exhibited cortisol at an altered concentration, in the collection periods (morning, afternoon and night). In the morning, 80.0\% ( $\mathrm{n}=20)$ of the caregivers did not present alterations in cortisol dosages, according to the reference values used ${ }^{35}$, whereas in the afternoon the percentage dropped to $72.0 \%(n=18)$ and $60.0 \%$ ( $\mathrm{n}=15$ ) at night, according to the circadian cycle of cortisol, evidenced in healthy individuals.

\section{Relationship between cortisol levels and questionnaire results}

Of the variables analyzed by the study, only the age of the caregivers was significantly correlated with the dose of salivary cortisol collected in the afternoon ( $\mathrm{r}=0.470 ; \mathrm{P}=0.018$ ), as well as when it was correlated with daily cortisol variation, corresponding to mean of the cortisol dosage in the three periods $(\mathrm{r}=0.403 ; \mathrm{P}=0.046)$ (Table 1$)$.

\section{Table 1. Correlation between the salivary cortisol level and its daily variation with the variables studied in caregivers of patients with Alzheimer's disease.}

\begin{tabular}{|l|l|l|l|l|l|l|}
\hline Cortisol level & IADLs & BDI $^{*}$ & SF-36* & CDR $^{\star *}$ & Relationship & Age $^{* *}$ \\
\hline Morning & -0.005 & 0.029 & -0.032 & -0.026 & $0.289^{* * *}$ & 0.192 \\
\hline Afternoon & -0.039 & 0.128 & 0.098 & 0.083 & 0.171 & 0.470 \\
\hline Evening & 0.115 & 0.177 & 0.342 & 0.001 & 0.160 & 0.388 \\
\hline Daily variation & 0.075 & 0.151 & 0.098 & 0.016 & $-0.311^{* * *}$ & 0.403 \\
\hline
\end{tabular}

*Pearson's correlation coefficient. ${ }^{* *}$ Spearman's rank correlation. ${ }^{* *} \mathrm{p}<0.05$ vs. age. IADL, Instrumental Activities of Daily Living. BDI, Beck Depression Inventory. SF-36, 36-Item Short-Form Health Survey; CDR, clinical disease rating. 
Figure 1, Figure 2 and Figure 3 show a positive correlation but no significant variation between nocturnal salivary cortisol $(\mu \mathrm{g} / \mathrm{dl})$ and the scores from AIVD, IDB and SF-36. Figure 4 shows a positive and significant correlation $(r=0.403 ; \mathrm{P}=0.046)$ between the daily variation of cortisol dosage $(\mu \mathrm{g} / \mathrm{dl})$ and the age of caregivers.
All correlations with significant $\mathrm{p}$ values were considered weak, owing to the sample size. However, it is possible to observe that cortisol values in the morning were correlated with the degree of kinship $(\mathrm{r}=0.289 ; \mathrm{p}<0.05)$. The correlation was weak but inverse between the degree of kinship and the daily variation of cortisol $\left(\mathrm{R}^{2}=-0.311 ; \mathrm{p}<0.05\right)$.

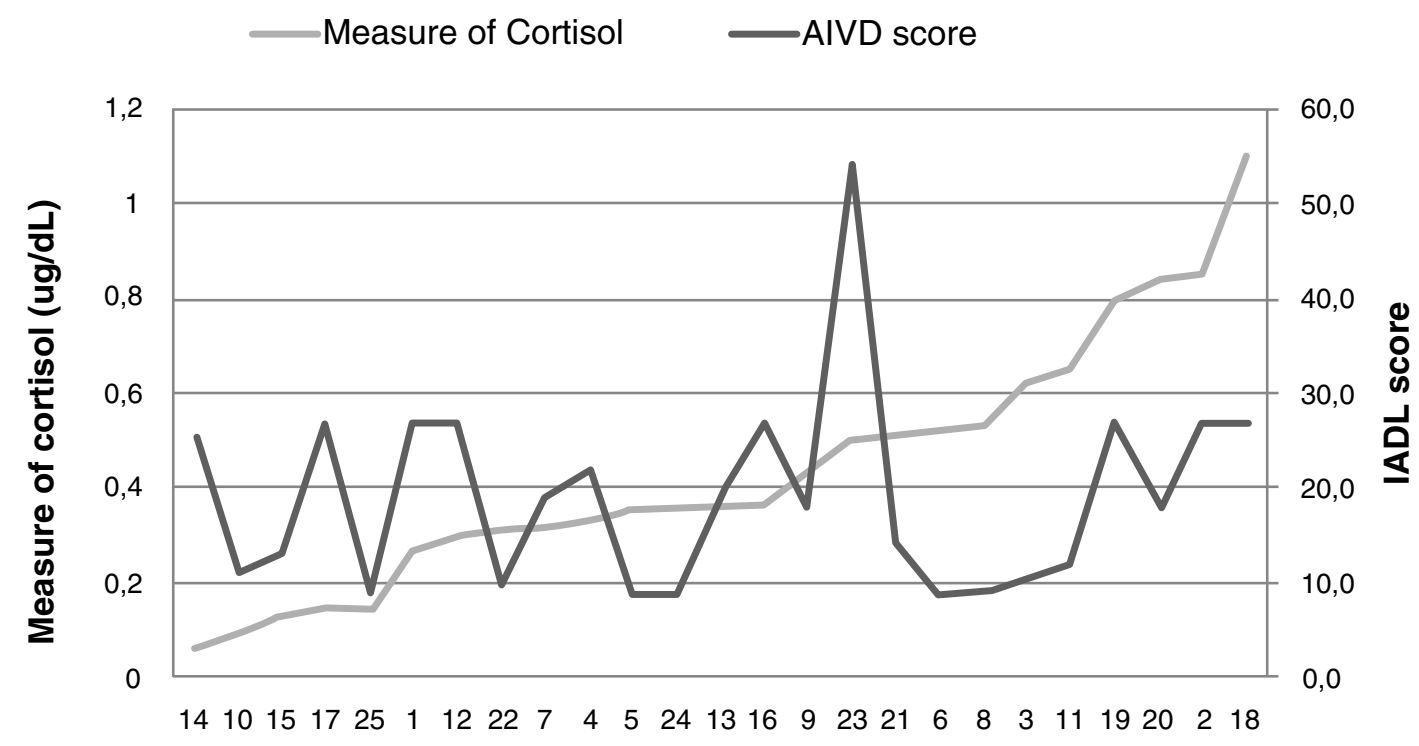

Caregivers of the elderly

Figure 1. Association between the Instrumental Activities of Daily Living (IADLs) score and the mean daily level of salivary cortisol of three periods (morning/afternoon/evening) $(P=0.412 / r=0.176)$ in caregivers of patients with Alzheimer's disease.

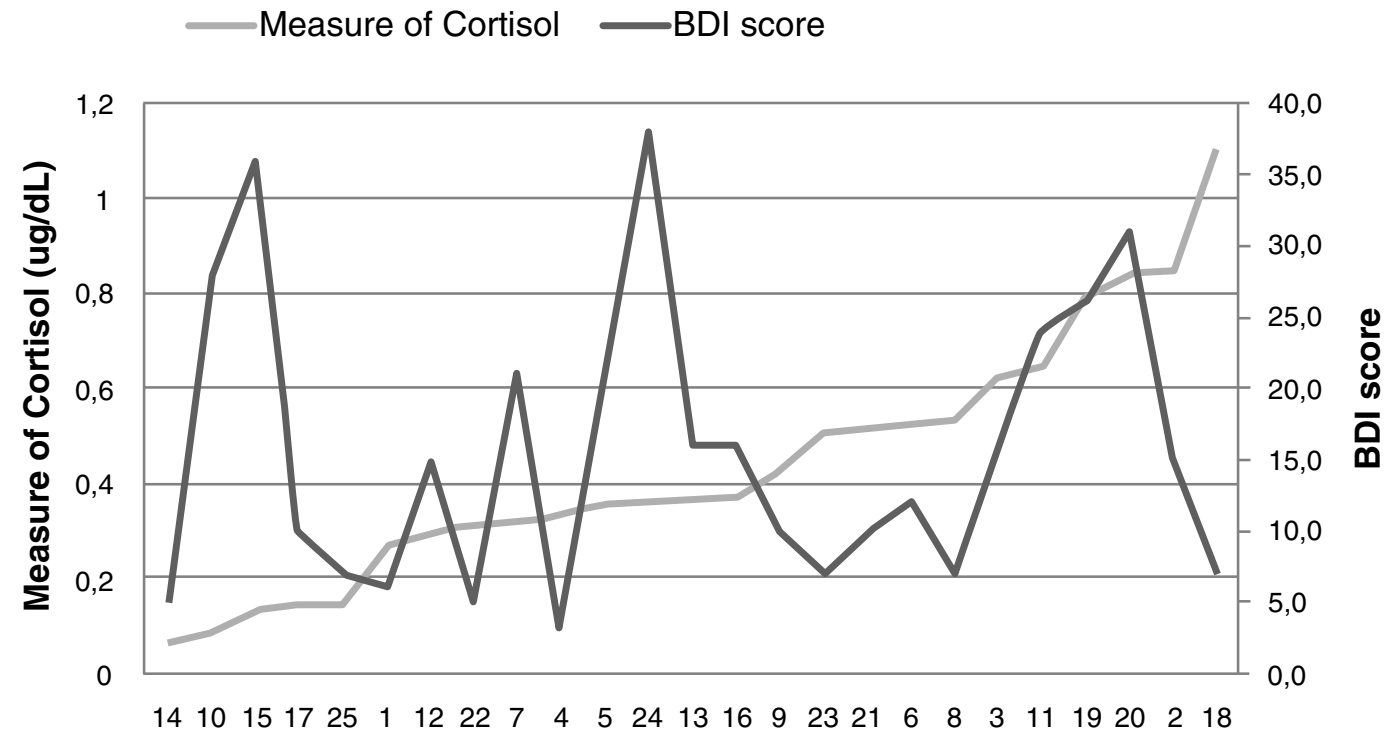

Caregivers of the elderly

Figure 2. Association between the Beck Depression Inventory (BDI) score and the mean daily level of salivary cortisol of three periods (morning/afternoon/evening) $(r=0.151 ; P=0.470)$ in caregivers of patients with Alzheimer's disease. 


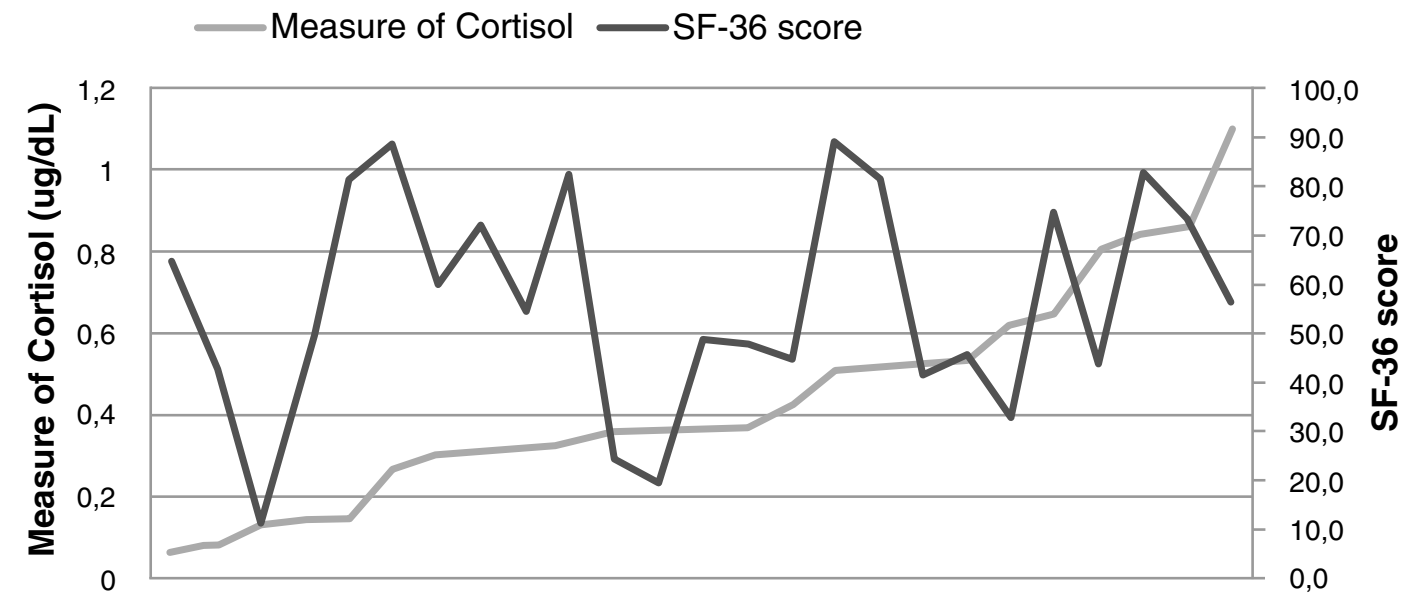

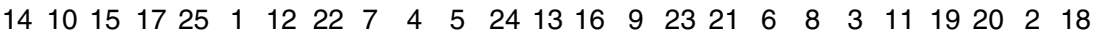

Caregivers of the elderly

Figure 3. Association between the 36-Item Short-Form Health Survey (SF-36) score, and the mean salivary cortisol daily level three times (morning/afternoon/evening) $(r=0.098 ; P=0.111)$ for caregivers of patients with Alzheimer's disease.

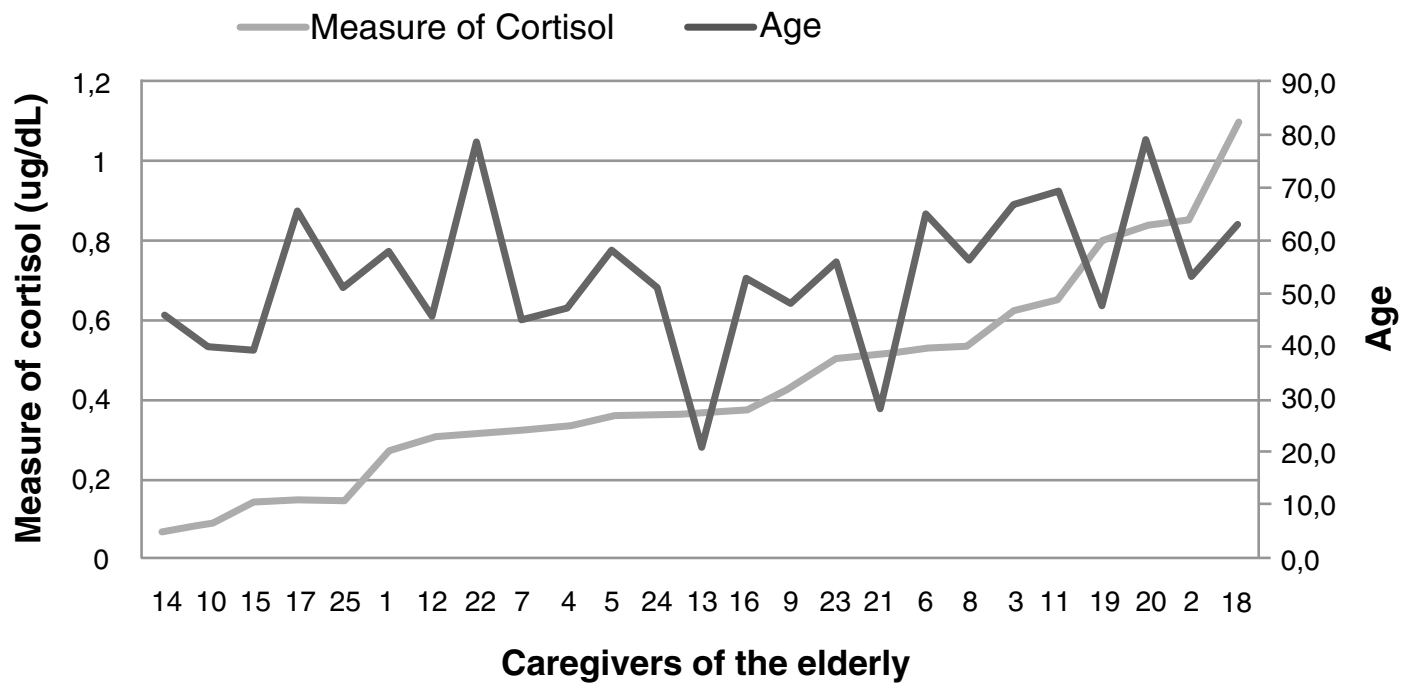

Figure 4. Association between age and mean daily level of salivary cortisol of three periods (morning/afternoon/evening) $(r=0.403$; $\mathrm{P}=0.046$ ) in caregivers of patients with Alzheimer's disease.

Table 2 shows the relationship between the CDR scores of the patients with $\mathrm{AD}$ and the corresponding mean salivary cortisol doses $(\mathrm{mg} / \mathrm{dl})$ of their caregivers. Mean values of salivary cortisol of the caregivers, measured in the morning and afternoon periods, remained below the cortisol values considered normal for these periods, which are approximately $0.69 \mu \mathrm{g} / \mathrm{dl}$ and $0.43 \mu \mathrm{g} / \mathrm{dl}$, respectively, for the three groups of investigated CDRs. This diverged from the mean cortisol scored at night, which remained above the reference value considered normal for this period, approximately $0.35 \mu \mathrm{g} / \mathrm{dl}$, for the three analyzed groups.

In a horizontal analysis of the table, the mean cortisol levels in the specific periods evaluated (morning, afternoon and evening) and the mean daily cortisol variation did not change significantly $(\mathrm{P}>0.05$ ) when associated with the CDR groups (Table 2). 
Table 2. Comparison between the clinical disease rating (CDR) of patients with Alzheimer's disease with the salivary cortisol level at different time points in the caregivers these patients.

\begin{tabular}{|l|l|l|l|l|}
\hline Cortisol level, $\boldsymbol{\mu g} / \mathbf{d l}$ & CDR1 & CDR2 & CDR3 & P-value* \\
\hline Morning & $0.42 \pm 0.13$ & $0.57 \pm 0.34$ & $0.45 \pm 0.35$ & 0.47 \\
\hline Afternoon & $0.31 \pm 0.09$ & $0.42 \pm 0.26$ & $0.39 \pm 0.28$ & 0.78 \\
\hline Evening & $0.48 \pm 0.51$ & $0.36 \pm 0.28$ & $0.44 \pm 0.37$ & 0.98 \\
\hline Daily variation & $0.40 \pm 0.16$ & $045 \pm 0.28$ & $043 \pm 0.29$ & 0.92 \\
\hline
\end{tabular}

Data are expressed as the mean $\pm \mathrm{SD}$. ${ }^{*}$ Calculated using the

Kruskal-Wallis test.

\section{Discussion}

Our study showed that daily salivary cortisol levels did not differ significantly when associated with the level of depression in caregivers of patients with $\mathrm{AD}$, suggesting that this is not a good marker of neuroendocrine response to mood disorders. It is understood that this may be related to intrinsic and extrinsic factors to the caregiver.

We found that the emotional caregiver burden, as measured by the BDI and SF-36 tests, was also not reflected in the levels of cortisol daily. Maria and Jeckel concluded that caregivers were more anxious, depressed and stressed than healthy, non-caregiving controls, although there was no increase in daily levels of salivary cortisol. On the other hand, previous research has found that hypo- and hypercortisolism is associated with depression and anger ${ }^{36-39}$.

One explanation for the discrepancy in the variation of cortisol levels may be related to difference in perception and adaptation to stress by the caregiver, or even the course of the condition to a chronic state ${ }^{40}$. Leggett et al., in a study conducted with 164 caregivers of individuals with dementia, found patterns of hypocortisolism in populations with chronic stress, in mothers who take care of adolescents with autism or other serious mental disorders, or the parents of patients with cancer, but did not obtain the same patterns of cortisol variation in situations of non-chronicity ${ }^{41}$.

It is understood that the mechanism of maintenance of homeostasis in the body in response to the experiences of the individual throughout their life, is a dynamic process and involves interactions between biological and psychosocial factors in a way that does not always result in neuroendocrine adaptation, since the physiological response is dependent on the reaction of individuals to adverse situations. Therefore, the regulatory factors of a possible onset of hormonal disorder are variable, since they are influenced by the humoral state, individual experiences, social level, intellectual capacity, lifestyle, genetics of the individual, religiosity, age and even the biological material used to evaluate the analyte ${ }^{39,43,44}$.

Cortisol is not the only steroid that undergoes changes in response to stress. Other hormones, such as $\mathrm{BDNF}^{45}$, DHEA ${ }^{18}$ and progesterone ${ }^{46}$, interact and influence mood in individuals. There are studies that already suggest that the cortisol-DHEA ratio is a better marker for cognitive alterations than cortisol or DHEA alone, for example ${ }^{47}$. A previous study has shown that increased cortisol-DHEA ratios are related to the cognitive decline observed in caregivers of patients with dementia ${ }^{48}$, and this is not observed for cortisol alone.

The differences in the age groups of experimental samples, as suggested by the observed effects of age demonstrated by this and other work $^{49,50}$ interfere with the circadian rhythm of cortisol. In this study, diurnal cortisol secretion followed a circadian rhythm, in line with normal conditions, in order to present higher levels of cortisol in the morning and decreasing levels throughout the day, for most cases. This is in accordance with the literature that predicts higher production of cortisol in the second half of the night, with a peak in the early hours of the morning and a progressive decrease during the day, with lower peaks during the first part of the night ${ }^{51}$. However, despite the positive correlation observed between the age of the caregiver and the level of cortisol in the afternoon, as well as in the mean cortisol of the three evaluated periods, cortisol changes with aging in humans are still considered controversial ${ }^{52}$.

A limitation of our study was the lack of assessment of the coping strategies of caregivers. The majority of studies, including those with $\mathrm{AD}$ caregivers and chronic stress models, evaluate these strategies through the Coping Inventory for Stressful Situations (CISS) ${ }^{53,54}$. The CISS study is fundamental to understand how stress interferes in people's health in order to verify their ability to adapt to this disorder ${ }^{55,56}$, which could help to understand daily cortisol dosages within normality for most of the sample in research. 
Other limitations of the study were the absence of data on the length of stay of the caregivers with the elderly patients affected by $\mathrm{AD}$, as well as the size of the sample in this study. These may have impaired the achievement of a significant correlation between the cortisol dosages evaluated and the other variables.

In conclusion, we found evidence that stress mechanisms are not necessarily linked to changes in the circadian rhythm of cortisol observed in caregivers of elderly individuals with AD. Therefore, we would suggest that this steroid hormone alone is not a reliable neuroendocrine marker for the disorder of depression. This evidence underscores the fact that the HPA axis does not have a standard relationship with exhaustive experiences and associated feelings of individuals. Taking into account past work $^{10,40,48,57,58}$, these findings present a broader discussion, in terms of evidence, of cortisol responsiveness to caregiver health and possible co-influencers, such as the age and the impact of the CDR evolution of these individuals.

In future studies it is important to outline other possible cortisol modulators as well as the downstream neurosteroids. In addition, a more detailed study of the type of stress that reaches this group of caregivers, as well as their ability to adapt and face adversity in front of their work, should be included in the next analyses. This work is important from a physiological and psychological point of view, to understand the hormonal effects linked to depression in humans. In addition, this study indicates that the focus of the health of caregivers of patients with $\mathrm{AD}$ should be expanded and efforts to understand how routine can reflect on their body in form of disease should be made.

\section{Data availability}

Raw data for this article are available on Open Science Framework (DOI: https://doi.org/10.17605/OSF.IO/DNTR7) ${ }^{59}$. Data are available under the terms of the Creative Commons Zero "No rights reserved" data waiver (CC0 1.0 Public domain dedication).

\section{Consent}

Each participant (patient and caregiver) gave written informed consent for inclusion in, and publication of, this study.

\section{Competing interests}

No competing interests were disclosed.

\section{Grant information}

This study was funded by the Association of studies, research and assistance to people with Alzheimer's disease (AEPAPA), the Araucaria Foundation and Coordination of Improvements of Higher Education Personnel (CAPES).

The funders had no role in study design, data collection and analysis, decision to publish, or preparation of the manuscript.

\section{Acknowledgements}

The authors would like to extend their gratitude to the Association of Studies, Research and Assistance to People with Alzheimer's Disease (AEPAPA) and to the Araucaria Foundation and Higher Education Personnel Improvement Coordination (CAPES).
1. Alzheimer's Association: 2013 Alzheimer's disease facts and figures. Alzheimers Dement. 2013; 9(2): 208-45. PubMed Abstract | Publisher Full Text

2. Gabriel KDEOF, Da J, Marques R, et al.: Avaliação das condições de saúde dos idosos alzheimer evaluation of health conditions of elderly and caregiving patients with alzheimer âftm s dementia. 2017; 18: 34-6. Reference Source

3. Hazzan AA, Ploeg J, Shannon $\mathrm{H}$, et al:: Association between caregiver quality of life and the care provided to persons with Alzheimer's disease: protocol for a systematic review. Syst Rev. 2013; 2(1): 17.

PubMed Abstract | Publisher Full Text | Free Full Text

4. De Oliveira Francisco Gabriel K, Marques Amaral Jdar, Carraro E, et al.: Dificuldades vivenciadas pelos cuidadores de alzheimer: uma revisão de literatura. (portuguese). Difficulties exp by alzheimer's caregivers a Lit Rev. 2015 12(3): 88-92.

Reference Source

5. Vitaliano PP: An Ironic Tragedy: Are Spouses of Persons with Dementia at Higher Risk for Dementia than Spouses of Persons without Dementia? J Am Geriatr Soc. 2010; 58(5): 976-8.

PubMed Abstract | Publisher Full Text | Free Full Text

6. Vitaliano PP, Murphy M, Young HM, et al.: Does caring for a spouse with dementia promote cognitive decline? A hypothesis and proposed mechanisms. J Am Geriatr Soc. 2011; 59(5): 900-8. PubMed Abstract | Publisher Full Text

7. Mariotti A: The effects of chronic stress on health: new insights into the molecular mechanisms of brain-body communication. Futur Sci OA. 2015; 1(3): FSO23.

PubMed Abstract | Publisher Full Text | Free Full Text
8. McEwen BS, Morrison JH: The Brain on Stress: Vulnerability and Plasticity of the Prefrontal Cortex over the Life Course. Neuron. 2013; 79(1): 16-29. PubMed Abstract | Publisher Full Text | Free Full Text

9. Vitaliano PP, Echeverria D, Yi J, et al:: Psychophysiological mediators of caregiver stress and differential cognitive decline. Psychol Aging. 2005; 20(3): 402-11.

PubMed Abstract | Publisher Full Text

10. Varilly P, Chandldler D: NIH Public Access. 2012; v(2): 265-75.

11. de Vugt ME, Jolles $\mathrm{J}$, van Osch $\mathrm{L}$, et al.: Cognitive functioning in spousal caregivers of dementia patients: findings from the prospective MAASBED study. Age Ageing. 2006; 35(2): 160-6. PubMed Abstract | Publisher Full Text

12. Palma KA, Balardin JB, Vedana G, et al.: Emotional Memory Deficit and its Psychophysiological Correlate in Family Caregivers of Patients With Dementia. Alzheimer Dis Assoc Disord. 2011; 25(3): 262-8. PubMed Abstract | Publisher Full Text

13. Henckens MJ, Pu Z, Hermans EJ, et al:: Dynamically changing effects of corticosteroids on human hippocampal and prefrontal processing. Hum Brain Mapp. 2012; 33(12): 2885-97. PubMed Abstract | Publisher Full Text

14. Adam EK, Vrshek-Schallhorn S, Kendall AD, et al:: Prospective associations between the cortisol awakening response and first onsets of anxiety disorders over a six-year follow-up--2013 Curt Richter Award Winner. Psychoneuroendocrinology. 2014; 44: 47-59. PubMed Abstract | Publisher Full Text | Free Full Text

15. Mcewen BS, Bowles NP, Gray JD, et al.: Mechanisms of stress in the brain. Nat Neurosci. 2015; 18(10): 1353-63. PubMed Abstract | Publisher Full Text | Free Full Text 
16. Sriram K, Rodriguez-Fernandez M, Doyle FJ 3rd: Modeling cortisol dynamics in the neuro-endocrine axis distinguishes normal, depression, and posttraumatic stress disorder (PTSD) in humans. PLoS Comput Biol. 2012; 8(2): e1002379.

PubMed Abstract | Publisher Full Text | Free Full Text

17. Kumar A: Long-Term Potentiation at CA3-CA1 Hippocampal Synapses with Special Emphasis on Aging, Disease, and Stress. Front Aging Neurosci. 2011; 3: 7. PubMed Abstract | Publisher Full Text | Free Full Text

18. Dong $\mathrm{Y}$, Zheng $\mathrm{P}$ : Dehydroepiandrosterone sulphate: Action and mechanism in the brain. J Neuroendocrinol. 2012; 24(1): 215-24. PubMed Abstract | Publisher Full Text

19. Childs E, DIDlugos A, De Wit $\mathrm{H}$ : Cardiovascular, hormonal, and emotiona responses to the TSST in relation to sex and menstrual cycle phase. Psychophysiology. 2010; 47(3): 550-9. PubMed Abstract | Publisher Full Text | Free Full Text

20. Gettler LT, Mcdade TW, Agustin SS, et al.: Progesterone and estrogen responsiveness to father-toddler interaction. Am J Hum Biol. 2013; 25(4): 491-8.

PubMed Abstract | Publisher Full Text

21. Maner JK, Miller SL, Schmidt NB, et al:: The endocrinology of exclusion: rejection elicits motivationally tuned changes in progesterone. Psychol Sci. 2010; 21(4): 581-8.

PubMed Abstract | Publisher Full Text

22. Schultheiss OC, Wirth MM, Stanton SJ: Effects of affiliation and power motivation arousal on salivary progesterone and testosterone. Horm Behav. 2004; 46(5): 592-9.

PubMed Abstract | Publisher Full Text

23. Wirth MM, Meier EA, Fredrickson BL, et al:: Relationship between salivary cortisol and progesterone levels in humans. Biol Psychol. 2007; 74(1): 104-7. PubMed Abstract | Publisher Full Text

24. Wirth MM: Beyond the HPA Axis: Progesterone-Derived Neuroactive Steroids in Human Stress and Emotion. Front Endocrinol (Lausanne). 2011; 2: 19. PubMed Abstract | Publisher Full Text | Free Full Text

25. Dyniewicz AM: Metodologia da pesquisa em saúde para iniciantes. São Caetano do Sul: Difusão Editora. 2007.

26. Pimienta FA, Simil GF, Tórres HO, et al:: Avaliação da qualidade de vida de aposentados com a utilização do questionário SF-36. Rev Assoc Med Bras. 2008; 54(1): 55-60.

Publisher Full Text

27. Lawton MP, Brody EM: Assessment of older people: self-maintaining and instrumental activities of daily living. Gerontologist. 1969; 9(3): 179-86. PubMed Abstract | Publisher Full Text

28. Caixeta L: Doenças de Alzheimer. 1 ed. VitalSource Bookshelf. ArtMed, 2012. Reference Source

29. Berg L: Clinical Dementia Rating (CDR). Psychopharmacol Bull. 1988; 24(4) 637-639.

PubMed Abstract

30. Inventory P: Inventory for Measuring Depression. 2013; 561-71.

31. Cunha JA: Manual da versão em português das Escalas Beck. São Paulo: Casa do Psicólogo, 2001.

32. dos Santos RL, Virtuoso Júnior JS: Reliability of the Brazilian version of the Scale of Instrumental. Rev Bras em Promoção Saúde. 2008; 21(4): 290-6.

33. Hughes $C P$, Berg L, Danziger WL, et al.: A new clinical scale for the staging of dementia. Br J Psychiatry. 1982; 140(6): 566-572. PubMed Abstract | Publisher Full Text

34. Morris JC: The Clinical Dementia Rating (CDR): current version and scoring rules. Neurology. 1993; 43(11): 2412-2412. PubMed Abstract | Publisher Full Text

35. Aardal E, Holm AC: Cortisol in saliva--reference ranges and relation to cortisol in serum. Eur J Clin Chem Clin Biochem. 1995; 33(12): 927-932. PubMed Abstract | Publisher Full Text

36. Barker ET, Greenberg JS, Seltzer MM, et al.: Daily stress and cortisol patterns in parents of adult children with a serious mental illness. Heal Psychol. 2012; 31(1): 130-4.

PubMed Abstract | Publisher Full Text | Free Full Text

37. Holland JM, Thompson LW, Cucciare MA, et al:: Cortisol outcomes among caucasian and latina/hispanic women caring for a family member with dementia: A preliminary examination of psychosocial predictors and effects of a psychoeducational intervention. Stress Heal. 2011; 27(4): 334-46. Publisher Full Text

38. Seltzer MM, Greenberg JS, Hong J, et al:: Maternal Cortisol Levels and Behavior Problems in Adolescents and Adults with ASD. J Autism Dev Disord. 2010; 40(4): 457-69.

PubMed Abstract | Publisher Full Text | Free Full Text
39. Outorado TESEDED, Maria C, Jeckel M: T d a p i c p d. 2006.

40. El-Farhan N, Rees DA, Evans C: Measuring cortisol in serum, urine and saliva - are our assays good enough? Ann Clin Biochem. 2017; 54(3): 308-322. PubMed Abstract | Publisher Full Text

41. Leggett AN, Zarit SH, Kim K, et al:: Depressive Mood, Anger, and Daily Cortisol of Caregivers on High- and Low-Stress Days. J Gerontol B Psychol Sci Soc Sci. 2015; 70(6): 820-9. PubMed Abstract | Publisher Full Text | Free Full Text

42. Dias R, Santos RL, Sousa MF, et al.: Resilience of caregivers of people with dementia: a systematic review of biological and psychosocial determinants. Trends Psychiatry Psychother. 2015; 37(1): 12-9. PubMed Abstract | Publisher Full Text

43. Claessens SE, Daskalakis NP, van der Veen R, et al.: Development of individua differences in stress responsiveness: An overview of factors mediating the outcome of early life experiences. Psychopharmacology (Berl). 2011; 214(1): $141-54$.

PubMed Abstract | Publisher Full Text | Free Full Text

44. Wong JD, Selzer MM, Greenberg JS, et al:: Stressful life events and daily stressors affect awakening cortisol level in midlife mothers of individuals with autism spectrum disorders. Aging Ment Health. 2012; 16(8): 939-49. PubMed Abstract | Publisher Full Text | Free Full Text

45. Issa G, Wilson C, Terry AV Jr, et al.: An inverse relationship between cortisol and BDNF levels in schizophrenia: Data from human postmortem and animal studies. Neurobiol Dis. 2010; 39(3): 327-33.

PubMed Abstract | Publisher Full Text

46. Gaffey $A E$, Wirth MM: Stress, rejection, and hormones: Cortisol and progesterone reactivity to laboratory speech and rejection tasks in women and men [version 2; referees: 2 approved]. F1000Res. 2014; 3: 208. PubMed Abstract | Publisher Full Text | Free Full Text

47. Jeckel CM, Lopes RP, Berleze MC, et al:: Neuroendocrine and immunological correlates of chronic stress in 'strictly healthy' populations. Neuroimmunomodulation. 2010; 17(1): 9-18.

PubMed Abstract | Publisher Full Text

48. Corrêa MS, Vedovelli K, Giacobbo BL, et al:: Psychophysiological correlates of cognitive deficits in family caregivers of patients with Alzheimer Disease. Neuroscience. 2015; 286: 371-82.

PubMed Abstract | Publisher Full Text

49. Roelfsema F, van Heemst D, Iranmanesh A, et al:: Impact of age, sex and body mass index on cortisol secretion in $\mathbf{1 4 3}$ healthy adults. Endocr Connect. 2017 6(7): 500-9.

PubMed Abstract | Publisher Full Text | Free Full Text

50. Lupien SJ, McEwen BS, Gunnar MR, et al.: Effects of stress throughout the lifespan on the brain, behaviour and cognition. Nat Rev Neurosci. 2009; 10(6): $434-45$.

PubMed Abstract | Publisher Full Text

51. Schiefelbein VL, Susman EJ: Cortisol levels and longitudinal cortisol change as predictors of anxiety in adolescents. J Early Adolesc. 2006; 26(4): 397-413. Publisher Full Text

52. Gomez F, Curcio LC, Benjumea MA: El eje hipotálamo-pituitaria-adrenal (HPA) al envejecer The hypothalamic pituitary adrenal axis (HPA) in aging Salivary cortisol in the elderly. Acta Med Colomb [online]. 2016; 41(2): 130-137. Reference Source

53. Orzechowska A, Zajaczkowska M, Talarowska M, et al.: Depression and ways of coping with stress: A preliminary study. Med Sci Monit. 2013; 19: 1050-6.

PubMed Abstract | Publisher Full Text | Free Full Text

54. lavarone A, Ziello AR, Pastore F, et al:: Caregiver burden and coping strategies in caregivers of patients with Alzheimer's disease. Neuropsychiatr Dis Treat. 2014: 10: 1407-13.

PubMed Abstract | Publisher Full Text | Free Full Text

55. Antoniazzi AS, Dell'Aglio DD, Bandeira DR: O conceito de coping: uma revisão teórica. Estud Psicol. 1998; 3(2): 273-94.

Reference Source

56. Mussumeci AA: Estresse, Coping e Experiências Emocionais: Uma Análise das Respostas de Enfrentamento do Casal. 2017; 21(1): 33-49. Reference Source

57. Yang G, Sau C, Lai W, et al:: HHS Public Access. 2015; 344(6188): 1173-8.

58. Corrêa MS, Giacobbo BL, Vedovelli K, et al:: Age Effects on Cognitive and Physiological Parameters in Familial Caregivers of Alzheimer's Disease Patients. PLoS One. 2016; 11(10): e0162619. PubMed Abstract | Publisher Full Text | Free Full Text

59. Emanuela B: DEPRESSION, QUALITY OF LIFE AND CORTISOL: A TRANSVERSAL STUDY OF ALZHEIMER'S PATIENTS CAREGIVERS. Open Science Framework. 2018

Data Source 


\section{Open Peer Review}

\section{Current Peer Review Status:}

\section{Version 1}

Reviewer Report 18 January 2019

https://doi.org/10.5256/f1000research.15713.r39244

(C) 2019 Sousa M. This is an open access peer review report distributed under the terms of the Creative Commons Attribution License, which permits unrestricted use, distribution, and reproduction in any medium, provided the original work is properly cited.

\section{Maria F.B. Sousa}

Center for Alzheimer's Disease, Institute of Psychiatry, Federal University of Rio de Janeiro, Rio de Janeiro, Brazil

This article addresses the related mechanisms between the hormonal systems of the hypothalamic-pituitary-adrenal axis, which produces cortisol. The study evaluated the relationship between the daily variation of salivary cortisol dosages and the level of stress in caregivers of patients with Alzheimer's disease (AD). It is an interesting article. However, some questions need to be clarified to improve the manuscript and make it clearer to the reader:

\section{Abstract:}

The authors wrote in the 'Conclusions' section: “...the stress mechanism may be more complex and depend on more factors than the levels of this hormone", so I suggest Methods: including in the 'Conclusions' section one or two factors to exemplify this.

There is this information that "In order to determine the size of the sample, we considered all patients that fit the inclusion criteria of the study and are serviced by AEPAPA". However, the inclusion and exclusion criteria are not clear. I suggest writing about the criteria used in Association for Research and Assistance to Patients with Alzheimer's (AEPAPA).

The authors concluded that "...the stress mechanism may be more complex and depend on more factors than the levels of this hormone". So, I would like to know more information about the caregivers' clinical comorbidities, because a clinical comorbidity can be an explanatory factor.

Is the work clearly and accurately presented and does it cite the current literature? Yes

Is the study design appropriate and is the work technically sound? Yes

Are sufficient details of methods and analysis provided to allow replication by others? 
Partly

If applicable, is the statistical analysis and its interpretation appropriate? Yes

Are all the source data underlying the results available to ensure full reproducibility? Partly

Are the conclusions drawn adequately supported by the results?

Yes

Competing Interests: No competing interests were disclosed.

I confirm that I have read this submission and believe that I have an appropriate level of expertise to confirm that it is of an acceptable scientific standard.

Reviewer Report 19 November 2018

https://doi.org/10.5256/f1000research.15713.r38013

(c) 2018 Wahbeh H. This is an open access peer review report distributed under the terms of the Creative Commons Attribution License, which permits unrestricted use, distribution, and reproduction in any medium, provided the original work is properly cited.

Helané Wahbeh

Institute of Noetic Sciences, Petaluma, CA, USA

Summary:

1. This is an interesting study evaluating salivary cortisol levels in Alzheimer's patient caregivers with a correlational analysis of multiple measures with morning, afternoon, and evening cortisol values. There are a number of issues with the paper that are rectifiable and would strengthen it enough for indexing acceptance.

Abstract:

1. This sentence in the abstract is very long and could be broken up for greater clarity: "Saliva samples were collected to assess the cortisol level of the caregivers three....caregivers and elderly patien

2. "this is not a good neuroendocrine marker of response to mood disorders" This is a very strong conclusion that does not seem warranted from the results of the study and considering the vast literature on HPA axis measures and mood disorders.

3. "dosage" Were they given cortisol? Maybe this should be "values"?

Introduction:

1. Change "The main reason" to "One reason". 


\section{Methods:}

1. What time did participants wake up in relation to their first sample collection? What time did they go to sleep the night before? Was this a usual amount of sleep for them? Did you collect any information about exercise during the day, illness, and smoking? All of these affect cortisol levels and should also be accounted for.

2. The statistical analysis would be more powerful using a linear regression model with all the variables of interest rather than separate simple correlations. Even if you stick to simple correlations, you would need to include a multiple comparison correction.

Results:

1. It would be helpful to put some of the demographic and/or questionnaire data into a table for easier readability.

2. The $x$-axis of Figures 1-4 is not clear. Is that showing time? Why are the numbers not in order? The figures are confusing and I'm not sure what relationship they are trying to show.

\section{Discussion:}

1. This is a very strong statement and not warranted considering the results of this one small study: "Our study showed that daily salivary cortisol levels did not differ significantly when associated with the level of depression in caregivers of patients with $A D$, suggesting that this is not a good marker of neuroendocrine response to mood disorders."

2. "possible onset of hormonal disorder" I don't think you have to have a hormonal disorder to have dysregulated cortisol values.

3. Under limitations - the authors could also add no measurement of perceived stress. You only measured one day of cortisol and only three time-points. You could add pros and cons for different cortisol collection methods here (salivary vs blood vs urine), diurnal vs 24-hour collections.

4. "Therefore, we would suggest that this steroid hormone alone is not a reliable neuroendocrine marker for the disorder of depression." Again, this is a very strong statement considering the size and scope of the study and results.

5. You need to include a discussion of your results in relation to other papers that have evaluated cortisol in caregivers. Here are other papers I found with a quick search that you have not cited (de Vugt et al., 2005 , Gallagher-Thompson et al., $2006^{2}$ and Wahbeh et al., $\left.2008^{3}\right)$. I am sure there are more.

\section{References}

1. de Vugt ME, Nicolson NA, Aalten P, Lousberg R, et al.: Behavioral problems in dementia patients and salivary cortisol patterns in caregivers.J Neuropsychiatry Clin Neurosci. 2005; 17 (2): 201-7 PubMed Abstract | Publisher Full Text

2. Gallagher-Thompson D, Shurgot GR, Rider K, Gray HL, et al.: Ethnicity, stress, and cortisol function in Hispanic and non-Hispanic white women: A preliminary study of family dementia caregivers and noncaregivers.Am J Geriatr Psychiatry. 2006; 14 (4): 334-42 PubMed Abstract I 


\section{Publisher Full Text}

3. Wahbeh H, Kishiyama SS, Zajdel D, Oken BS: Salivary cortisol awakening response in mild Alzheimer disease, caregivers, and noncaregivers.Alzheimer Dis Assoc Disord. 22 (2): 181-3 PubMed Abstract | Publisher Full Text

Is the work clearly and accurately presented and does it cite the current literature? Partly

Is the study design appropriate and is the work technically sound? Partly

Are sufficient details of methods and analysis provided to allow replication by others? Yes

If applicable, is the statistical analysis and its interpretation appropriate? Partly

Are all the source data underlying the results available to ensure full reproducibility? Yes

Are the conclusions drawn adequately supported by the results? Partly

Competing Interests: No competing interests were disclosed.

I confirm that I have read this submission and believe that I have an appropriate level of expertise to confirm that it is of an acceptable scientific standard, however I have significant reservations, as outlined above.

The benefits of publishing with F1000Research:

- Your article is published within days, with no editorial bias

- You can publish traditional articles, null/negative results, case reports, data notes and more

- The peer review process is transparent and collaborative

- Your article is indexed in PubMed after passing peer review

- Dedicated customer support at every stage

For pre-submission enquiries, contact research@f1000.com 